\title{
Influence of Vitreal Reflux on Intraocular Pressure After Intravitreal Application of Bevacizumab
}

\author{
Nebojša Đogatović, ${ }^{1}$ Vladimir Račić, ${ }^{1}$ Ernesta Potkonjak, ${ }^{1}$ Miloš Milićević, ${ }^{1}$ Dajana
} Abdulaj, ${ }^{1}$ Bojan Kozomara ${ }^{1}$

\section{Abstract}

Background/Aim: Intravitreal drug injection cause an increase in intraocular pressure (IOP). The increase in IOP is directly proportional to the volume of drug injected into the eye and inversely to the vitreal reflux. The mixture of fluid, presents as a subconjunctival bleb, composed of vitreous and injected drug is called vitreal reflux. In this study changes in IOP after intravitreal injection of bevacizumab in relation to the vitreous regurgitation were observed.

Methods: This prospective study involved 50 patients (57 injections). Bevacizumab was administered intravitreally at a dose of $1.25 \mathrm{mg} / 0.05 \mathrm{~mL}$. According to the type of disease, patients with diabetic macular oedema, proliferative diabetic retinopathy, age-related macular degeneration, retinal vein occlusion, choroidal neovascularisation and central serous chorioretinopathy were included. They were divided into two groups - the first one without vitreal reflux and the second one with vitreal reflux. IOP values were measured at baseline, right after drug application and 20 min thereafter. Results: The reference value range of IOP values were $10-21 \mathrm{mmHg}$ and so were the average baseline values in both experimental groups of patients $(15.81 \pm 3.50 \mathrm{mmHg})$. In the experimental group without reflux post application mean values of IOP at 0 and $20 \mathrm{~min}$ were $50 \pm 9.65$ and $18.54 \pm 5.06 \mathrm{mmHg}$, respectively. In the experimental group with reflux post application mean IOP values after 0 and 20 min were $36 \pm 8.68$ mmHg and $18.91 \pm 4.82 \mathrm{mmHg}$, respectively.

Conclusions: Following intravitreal bevacizumab application, a significant increase in IOP occurs. After 20 minutes the IOP values spontaneously decreased below $25 \mathrm{mmHg}$ in both groups and there was no significant difference in comparison with the baseline values. Vitreus reflux is a major factor in short-term post-injection IOP elevation, but not from the longer-term perspective.

Key words: intraocular pressure, intravitreal injection, anti-VEGF, bevacizumab, vitreal reflux.

\section{Introduction}

Intravitreal drug delivery is a very efficient method for treatment of many different ophthalmic diseases, including diabetic retinopathy, diabetic maculopathy, senile macular degeneration or any other macular disease that may benefit from anti-vascular endothelial growth factors (anti-VEGF) therapy.
(1) Eye Clinic "Svjetlost", Banja Luka, the Republic of Srpska, Bosnia and Herzegovina

Correspondence:

NEBOJŠA ĐOGATOVIĆ

E: nebojsa@svjetlost-banjaluka.ba M: +38766879 302

\section{ARTICLE INFO}

Received: 24 March 2020

Revision received: 5 June 2020 Accepted: 7 June 2020 
decreased retinal circulation around the papilla and within the papilla itself, in proportion to the size of the pressure. ${ }^{2}$ There are a lot of reports about levels of IOP that are safe after intravitreal anti-VEGF injection. ${ }^{3-7}$ Vitreal reflux was the major factor that impacts short term post injection IOP rise. ${ }^{8}$ Studies of ranibizumab (Lucentis ${ }^{\circledR}$, Novartis/Genentech Inc, USA) showed at two-year follow-up that there were no long-term changes in IOP values. ${ }^{9}$ This study also reported that at 60 min post-injection, less than $20 \%$ of patients had an elevated IOP of $30 \mathrm{mmHg}$ or higher. The report on escalating doses of ranibizumab showed no changes in IOP in the follow-up period of at least 4 months. ${ }^{10}$ Bevacizumab (Avastin ${ }^{\circledR}$, Roche/Genentech Inc, USA) is an off-label drug for intraocular treatment of many retinal diseases. Although bevacizumab causes an increase in IOP it never causes complete occlusion of the central retinal artery. $^{5}$

The aim of the present clinical trial was to observe changes in intraocular pressure after intravitreal application of anti-VEGF drug related to the presence or absence of the vitreal reflux.

\section{Methods}

This was a prospective clinical study in which patients received an intravitreal drug of anti-VEGF at the Eye Clinic "Svjetlost" Banja Luka, the Republic of Srpska, Bosnia and Herzegovina, from March to June 2019. Patients were asked to participate in this study if they were over 18 years of age. This clinical study was approved by the Ethics Committee of the Eye Clinic "Svjetlost" (Decision No 04/2019). Exclusion criteria were: patients with active uveitis, patients who have received intravitreal or subtenon triamcinolone in the last 6 months and patients diagnosed with any type of glaucoma.

Every patient was subjected to the following tests before entering the operating room for intravitreal drug injection: best corrected visual acuity (BCVA), slit lamp examination and IOP examination.

Intravitreal drugs application was performed in the operating room by using aseptic techniques. Topical anaesthesia in the form of tetracaine was applied, then the eye was sterilised with povidone iodine (5\%) and a lid speculum was inserted. Intravitreal injection of bevacizumab $0.05 \mathrm{~mL}$ was instilled with a 30-gauge needle through the pars plana area, inferotemporal 3.5-4.0 mm of limbus. After the needle entered into the eye $1.0-1.5 \mathrm{~cm}$, the drug was administrated. Studies have shown that the frequency of vitreal reflux does not depend on whether a 30 or 32 guage needle was used. ${ }^{11} \mathrm{~A}$ vitreal reflux is defined as any accumulation of subconjunctival fluid after intravitreal drug application. After injection, a sterile cotton swab was placed over the injection site. IOP was measured at baseline, immediately after drug injection and 20 min thereafter. The IOP was measured in the same position and by the same examiner with an Icare ${ }^{\circledR}$ PRO rebound tonometer model (Icare, Tiolat Oy, Helsinki, Finland).

The baseline values and individual values of IOP at each time-point were analysed using a paired t-test.

\section{Results}

Data from 57 eyes of 50 patients were analysed. Mean patient age was $68 \pm 8$. According to the prevalence of retinal diseases: 18 eyes (31.5\%) with diabetic macular oedema, 15 eyes (26.31\%) with proliferative diabetic retinopathy-vitreous haemorrhage, 15 eyes (26.31\%) with exudative age-related macular degeneration, 6 eyes $(10.52$ $\%)$ with retinal vein occlusion-related macular oedema, 1 eye $(1.75 \%)$ with chronic central serous chorioretinopathy and 2 eyes $(3.50 \%)$ with idiopathic choroidal neovascularisation. Intravitreal injection of bevacizumab $0.05 \mathrm{~mL}$ was performed. Post-injection vitreous regurgitation was confirmed in $33(57.9 \%)$ of 57 eyes (Table 1$)$.

Table 1: Incidence of disease and vitreal reflux after intravitreal injection of bevacizumab

\begin{tabular}{lcrr}
\hline Disease & $\begin{array}{r}\text { Number of } \\
\text { eyes (\%) }\end{array}$ & $\begin{array}{r}\text { Number of } \\
\text { eyes with } \\
\text { reflux }\end{array}$ & $\begin{array}{r}\text { Number of } \\
\text { eyes without } \\
\text { reflux }\end{array}$ \\
\hline Diabetic macular oedema & $18(31.5)$ & 10 & 8 \\
\hdashline Proliferative diabetic retinopathy & $15(26.31)$ & 9 & 6 \\
\hdashline Age-related macular degeneration & $15(26.31)$ & 7 & 8 \\
\hdashline Retinal vein occlusion & $6(10.52)$ & 5 & 1 \\
\hline Choroidal neovascularisation & $2(3.50)$ & 1 & 1 \\
\hdashline Central serous chorioretinopathy & $1(1.75)$ & 1 & 0 \\
\hline Total & $\mathbf{5 7 ( 1 0 0 . 0 0 )}$ & $\mathbf{3 3}$ & $\mathbf{2 4}$ \\
\hline
\end{tabular}




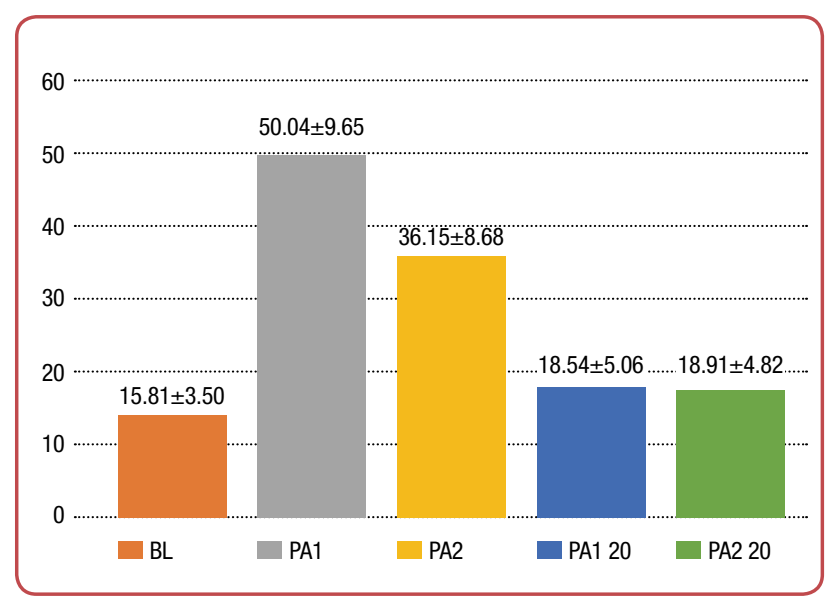

Figure 1: Intarocular pressure (IOP) before and after intravitreal application of bevacizumab

$B L$ - baseline value before application; $P A 1$ - post application value in the group 1 ; PA2 - post application value in the group 2; PA1 20-20 minutes post application value in the group 1; PA2 20-20 minutes post application value in the group 2

Baseline IOP values did not deviate from normal values which are within the range of $10-21$ mmHg. The mean pre-application value of IOP was $15.81 \pm 3.50 \mathrm{mmHg}$. The mean value of IOP immediately after application was $50.04 \pm 9.65$ $\mathrm{mmHg}$ in the group 1 (group without vitreal reflux) and $36.15 \pm 8.68 \mathrm{mmHg}$ in the group 2 (group with vitreal reflux) immediately after the injection. The IOP value immediately after intravitreal drug injection was significantly higher than the pre-injection IOP value $(\mathrm{p}<0.001)$; there was also a significant difference in post-application IOP between the reflux and non-reflux groups. After 20 min there was no significant difference between the both groups, as well as no significant clinical difference from the pre-application IOP values $(18.54 \pm 5.06 \mathrm{mmHg}$ in the group 1 and $18.91 \pm 4.82 \mathrm{mmHg}$ in the group 2) (Figure 1).

\section{Discussion}

Intravitreal drug injection of anti-VEGF is a common and widespread way of treatment of various ophthalmic diseases. The mean difference between IOP value before and immediately after drug application was $32.64 \pm 17.40 \mathrm{~mm} \mathrm{Hg}$ in the group 1 and $26.21 \pm 9.50 \mathrm{mmHg}$ in the group 2 . The IOP changes that occur after intravitreal anti-VEGF drug application are usually transient and the values return to the almost normal values after a short period $(<25-30 \mathrm{~mm} \mathrm{Hg}$ within 20 min), irrespective of whether there was a reflux or not. A prolonged elevation of IOP was not found. Some researchers report that there is a risk of in- creasing IOP in patients who received more than 29 injections, compared with those who received less than 12 injections. ${ }^{12}$

The results obtained in the present study are consistent with those of similar studies., ${ }^{5}$ In these studies, IOP values were monitored $30 \mathrm{~min}$ after drug application and in the following days. Other studies have also shown that a transient IOP spike occurs, and that additional IOP-lowering interventions such as paracentesis are not required. ${ }^{4-9}$

The results indicate that the presence or absence of vitreal reflux does not participate in the ultimate value of IOP, which in both cases is within the allowed value range. Tamponade with a cotton swab after intravitreal drug injection does not always cause a complete blockage of reflux. Even when cotton swabs were used for tamponade, there was sometimes a vitreous reflux, while in other cases, without a tamponade, there was no vitreous reflux. Irrespective of whether the tamponade was used or not and no matter whether there was a vitreous reflux or not, the ultimate IOP values are similar, with no significant difference between them after $20 \mathrm{~min}$.

This study has its limitations in the form of a short follow-up time and a small number of intravitral injections.

\section{Conclusion}

Intravitreal drug injection causes a significant increase in IOP. Increased IOP values are spontaneously lowered to the reference values without leading to a central retinal artery occlusion. This outcome was found irrespective of the absence or presence of the post-injection vitreal reflux.

\section{Acknowledgements}

None.

\section{Conflict of interest}

None. 


\section{References}

1. Quigley HA, Anderson DR. Distribution of axonal transport blockade by acute intraocular pressure elevation in the primate optic nerve head. Invest Ophthalmol Vis Sci 1977;16:640-4.

2. Michelson G, Groh MJ, Langhans M. Perfusion of the juxtapapillary retina and optic nerve head in acute ocular hypertension. Ger J Ophthalmol 1996;5:315-21.

3. Benz MS, Albini TA, Holz ER, Lakhanpal RR, Westfall AC, Iyer $\mathrm{MN}$, et al. Short-term course of intraocular pressure after intravitreal injection of triamcinolone acetonide. Ophthalmology 2006;113:1174-8.

4. Bakri SJ, Pulido JS, McCannel CA, Hodge DO, Diehl N, Hillemeier J. Immediate intraocular pressure changes following intravitreal injections of triamcinolone, pegaptanib, and bevacizumab. Eye (Lond) 2007;23:181-5.

5. Falkenstein IA, Cheng L, Freeman WR. Changes of intraocular pressure after intravitreal injection of bevacizumab (Avastin). Retina 2007;27:1044-7.
6. Hollands H, Wong J, Bruen R, Campbell RJ, Sharma S, Gale J. Short-term intraocular pressure changes after intravitreal injection of bevacizumab. Can J Ophthalmol 2007;42:807-11.

7. Kim JE, Mantravadi AV, Hur EY, Covert DJ. Short-term intraocular pressure changes immediately after intravitreal injections of anti-vascular endothelial growth factor agents. Am J Ophthalmol 2008;146:930-4.

8. Uvar E, Ulas F, Sahin S, Celebi S. Major factors affecting intraocular pressure spike after intravitreal ranibizmab injection: vitreus reflux and its amount. Eur J Ophthalmol 2019;29(4):361-7.

9. Rosenfeld PJ, Brown DM, Heier JS, Boyer DS, Kaiser PK, Chung CY, et al. Ranibizumab for neovascular age-related macular degeneration. New England J Med 2006;355:1419-31.

10. Rosenfeld PJ, Heier JS, Hantsbarger G, Shams N. Tolerability and efficacy of multiple escalating doses of ranibizumab (Lucentis) for neovascular age-related macular degeneration. Ophthalmology 2006;113:623-32. 